\title{
Variation and Developing Variation under a Transformational Perspective
}

\section{Variação e Variação Progressiva sob uma Perspectiva Transformacional}

\author{
Carlos Almada \\ Universidade Federal do Rio de Janeiro
}

\begin{abstract}
The present article introduces the current version of an analytical model, which proposes a transformational conception for musical variation. According to this perspective, an archetypical variation is considered as a generic function capable to transform a referential musical idea into another one to which is related by some degree of similarity. The study addresses a number of co-related concepts, classifications, and assumptions whose interaction aims at consolidating this new theoretical formulation. The last section presents a typology for Schoenberg's principle of developing variation under the transformational point of view.
\end{abstract}

Keywords: Variation and Developing variation; Model of Derivative Analysis; Transformational Theory

Resumo: Este artigo apresenta a versão atual de um modelo analítico que propõe uma concepção transformacional para a variação musical. De acordo com tal perspectiva, uma variação arquetípica é considerada como uma função genérica capaz de transformar uma ideia musical referencial em outra a ela relacionada por alguma similaridade. O estudo aborda vários conceitos, classificações e premissas correlatos, cuja interação busca consolidar essa nova formulação teórica. A última seção apresenta uma tipologia para o princípio Schoenberguiano de variação progressiva sob o ponto de vista transformacional.

Palavras-chave: Variação e Variação Progressiva; Modelo de Análise Derivativa; Teoria Transformacional 
MUSICA THEORICA Revista da Associação Brasileira de Teoria e Análise Musical 2019, v. 4, n. 1, p. 30-61 - Journal of the Brazilian Society for Music Theory and Analysis@ TeMA 2019 - ISSN 2525-5541

\section{Introduction}

This article integrates a broad research project whose main goal is the systematical study of musical variation. Initiated in 2011, the research has been constantly developed through adoption of new concepts, premises, and technological strategies, being subdivided into two basic approaches, analytical and compositional. The pursuing of the analytical approach, consolidated as a Model of Derivative Analysis (identified by the acronym MDA), has resulted in a considerable expansion of the theoretical scope of the research, being applied and improved in a number of practical studies. ${ }^{1}$ The current version of MDA explores a new investigative path, by connecting musical variation of the Transformational Theory, inspired by studies by David Lewin (1987), Michael Schiano (1992), and Steven Rings (2011).

The mutually complementary principles of Grundgestalt and developing variation play a central role in MDA's theoretical framework, and are also incorporated to the transformational approach. Both concepts were elaborated by Austrian composer and theoretician Arnold Schoenberg (1874-1951), constituting probably the most far-reaching of his numerous contributions to music theory. The binomial Grundgestalt-developing variation forms a powerful analytical construct associated with an organicist and economic conception of musical creation, a characteristic trait present in a large part of the music of Austro-German Romantic tradition, represented especially by Beethoven, Brahms, and Schoenberg himself. Essentially, a Grundgestalt of an organicallyconstructed musical piece introduces the basic elements from which ideally all material structures (motives, themes, and even subsidiary unities) could be obtained, through intensive use of derivative and progressive procedures, namely the techniques of developing variation. Under this perspective developing variation (from now on DV) can be seen as a highly dynamic process, employed not only for producing new, related material, but also as an important structuring force that acts on the organization of the piece. ${ }^{2}$ The transformational potentiality of DV is evident, which will be here properly explored.

\footnotetext{
${ }^{1}$ See especially Almada (2010; 2011; 2013; 2016), Mayr (2018), and Mayr; Almada (2016; 2017).

${ }^{2}$ Since the death of Schoenberg, both principles have been largely studied by a number of authors, covering a wide spectrum of approaches. See, for example Joseph Rufer (1952), David Epstein (1980), Patricia Carpenter (1983), Walter Frisch (1984), Severine Neff (1984), Michael Schiano
} 
The present article aims to introduce the basis of MDA's current configuration. The first section examines variation as a generic transformational function, proposing a formalization supported by some basic concepts and definitions. The notion of abstract variation, a crucial aspect of the research as a whole, is on the focus of the next section, followed by a description of the concept of transformational operations, the very agents of variation, according to the present conception. Section four presents processes and graphs related to transformational analysis and derivative network. The last section addresses briefly developing variation as adapted to the new format of MDA, which leads to the elaboration of a typology based on the temporal dimension.

\section{Derivative work}

Firstly, I define a musical idea ${ }^{3}$ as a short melodic sequence, relatively complete in itself, in which pitch and temporal structures play a special role. Let these structures be classified as the primary domains of the musical idea. The harmonic context in which the musical idea is (explicitly or not) inserted is considered its secondary domain. ${ }^{4}$

Let us consider that all imaginable musical ideas form a (conceptually infinite) set $S$. In the present context, variation is a generic function $V: S \rightarrow S$, which when applied to a referential musical idea $\mathrm{P}$ (stands por "parent") maps it to another member of S, the musical idea C ("child"), such that both can be related by some degree of similarity. ${ }^{5}$ Therefore, $\mathrm{C}$ is a transformation (or derivation) of

(1992), Jack Boss (1992), Ethan Haimo (1990, 1997), Stephen Collison (1994), Yuet Ng (2005), and Brent Auerbach (2005).

${ }^{3}$ I adopt here basically Schoenberg's definition of musical idea: "A musical idea (...), though consisting of melody, rhythm, and harmony, is neither one nor the other alone, but all three together" (Schoenberg 1984, p. 288).

${ }^{4}$ Evidently, the model could also include other secondary domains, like timbre, dynamics, texture, etc., which would contribute to increase largely its complexity. Aiming at simplicity and concision, I opted therefore to select only harmonic context for this category. The notion of domains can be associated with the concept of (primary and secondary) parameters, proposed by Leonard Meyer (1989).

${ }^{5}$ The relation of similarity is expressed by a real number between 0 (complete divergence) and 1 (identity relation). The measurement of similarity between two related musical ideas is a central aspect of the new configuration of MDA, being the subject of an article in preparation. This specific issue will not be addressed in the present study. 
MUSICA THEORICA Revista da Associação Brasileira de Teoria e Análise Musical 2019, v. 4, n. 1, p. 30-61 - Journal of the Brazilian Society for Music Theory and Analysis@ TeMA 2019 - ISSN 2525-5541

$\mathrm{P}$ by action of function V. C can also be named a variant of $\mathrm{P}$ or simply a derived idea (Figure 1). The adjective "generic" that qualifies the noun "function" in the definition of $\mathrm{V}$ reflects both assumptions that $\mathrm{P}$ is in some way transformed by the action of $\mathrm{V}$ (i.e., it does not matter yet how) ${ }^{6}$ and that $\mathrm{C}$, the output of this transformation, is related to the input $\mathrm{P}$ by some degree of similarity. In other words, $\mathrm{V}$ generically represents all possible manners in which $\mathrm{P}$ can be transformed into C. ${ }^{7}$

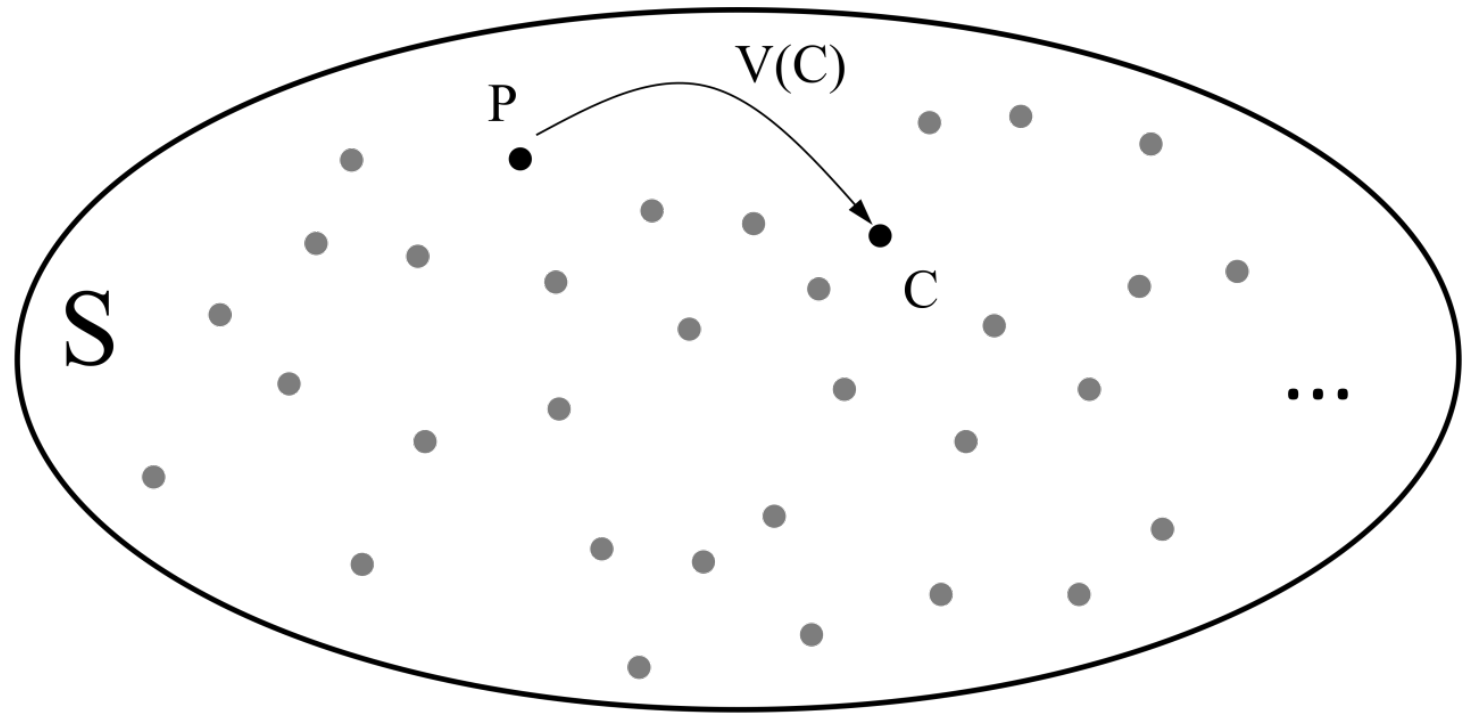

Figure 1: Graphical representation of the action of function V

Algebraically, it is then possible to express $\mathrm{C}$ in function of $\mathrm{P}$.

$$
C=V(P)
$$

\section{Equation 1}

The syntactic ordered interaction of the three elements, $\mathrm{P}, \mathrm{V}$, and $\mathrm{C}$ will be from now on referred as a derivative work. Figure 2 proposes the archetypical representation of a derivative work, as a more concise version of the scheme of Figure 1. Notice how the similarity relation between $P$ and $C$ is evidenced by the dashed line and the symbol Sp/c. This representation will be resumed in the fourth

\footnotetext{
${ }^{6}$ A detailed investigation about the possible manners that transformations may occur is a part important of this proposal, to be examined in the section 3 .

7 Put another way, $\mathrm{V}$ is also a set that congregates all possible types of actions (transformations) capable to send a given $\mathrm{P}$ to any possible variant $\mathrm{C}$. From this, we infer that set $\mathrm{V}$ is also conceptually infinite.
} 
section of this article, being adapted to the concept of archetypical developing variation.

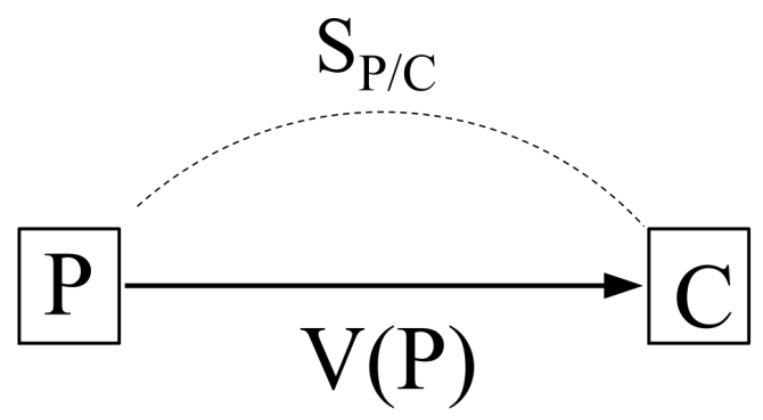

Figure 2: Action of the function $\mathrm{V}$ on $\mathrm{P}$, resulting in the variant $\mathrm{C}$

\section{Decomposable variation}

A derivative work can operate in two basic levels:

- Holistic: when $\mathrm{V}$ acts on the indivisible structure of $\mathrm{P}$ (i.e., encompassing the three domains as a whole).

- Decomposable: ${ }^{8}$ when $\mathrm{V}$ acts on isolated domains of $\mathrm{P}$, letting eventually (but not necessarily) the remaining unaltered.

The notion of holistic variation is reasonably self-explanatory, corresponding to what the common sense would consider "ordinary" variation (Fig. 3 exemplifies some possible holistic transformations of a referential idea P).

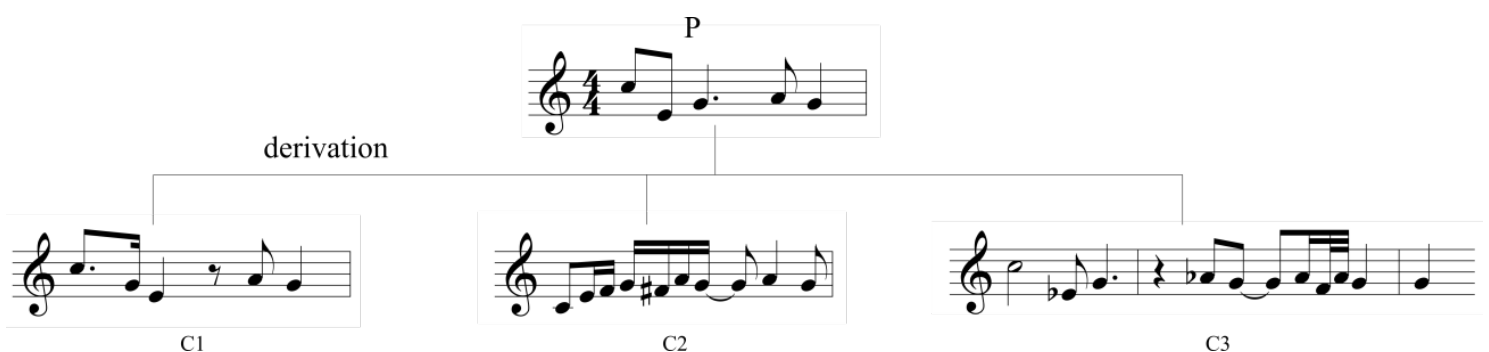

Figure 3: Examples of holistic variation

On the other hand, decomposable variation is not so intuitive and, therefore, deserves a more profound examination.

A central premise of MDA is that a large percentual of derivative work in a musical piece involve an isolated structural domain (think of a simple

8 The adjectives "holistic" and "decomposable" substitute for, respectively, "concrete" and "abstract", used in previous versions of MDA. 
intervallic inversion of a melody maintaining the original rhythmic configuration, for example). In other words, the process of derivation in this case is mediated by a previous stage of abstraction. As shown in Figure 4, pitch and rhythmic "essences" are abstracted from $\mathrm{P}$, respectively, $\mathrm{P}^{\prime}$ and $\mathrm{P}$ ", ${ }^{9}$ becoming in turn referential for independent types of derivation. For a sake of simplicity, let secondary domain of harmony (omitted in the examples) be maintained unaltered along the process.

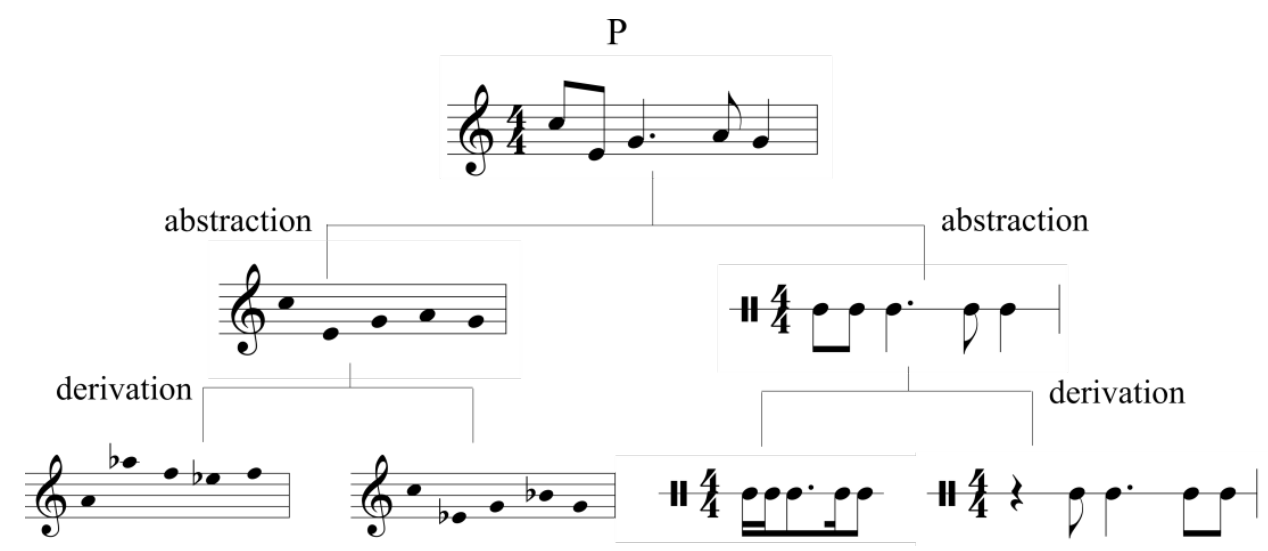

Figure 4: Examples of decomposable variation.

As a basic consideration, the primary domains of pitch and rhythm are taken as privileged in decomposable variation, letting the secondary harmony subordinated to them. Given this, supported by a combination of theoretical knowledge, information from literature, and analytical experience, I argue that, in general, pitch is the most permeable structural domain to the effects of variation. On the other hand, rhythmic figures have the tendency to be preserved (or only superficially transformed) in meaningfully related motivic/thematic unities, since normally they are the main responsible for the characterization of musical ideas themselves. More radical rhythmic variations can, of course, be applied along a derivative process, but almost inevitably they cause deeper distinction between referential and derived forms ( $\mathrm{P}$ and $\mathrm{C}$, in the present terminology) in opposition to the more common cases of smooth or gradual transformations. From this, a logical conclusion can be drawn: temporal changes (i.e., rhythmic and metric), though statistically less common than those involving pitch, are potentially more likely of transforming a given referential idea.

\footnotetext{
9 These are intuitive, but provisory labels that will be further replaced by more precise and adequate terms.
} 
The essential process of decomposable variation is performed by three sequential phases, described as follows:

1. Abstraction: in which the content of a domain is isolated from idea $\mathrm{P}$, becoming potential basis for further abstract derivation;

2. Derivation: in which the process of variation properly occurs, being applied to the abstracted, referential unity(ies) and resulting into another abstracted, derived unity(ies);

3. Re-integration: in which the abstracted domains (either those transformed or not) are recombined to form a definitive derived (concrete) idea C. ${ }^{10}$

Figure 5 proposes a graphical schematization of decomposable variation, using new conventions, symbols and terminology: concrete musical ideas ( $\mathrm{P}$ and C) are represented by solid-line rectangles; abstracted ideas (p, t, and h, standing for the domains of "pitch", "time", and "harmony") are represented by dashedline rectangles; and derived abstract ideas are numbered inside gray, dashed-line rectangles.

\footnotetext{
${ }^{10}$ The re-integration is observed in the foreground level, i.e., the score, while the other two levels - abstraction and derivation - correspond to analytical constructs that many times exist only as hypothesis (this aspect will be better discussed further on).
} 
MUSICA THEORICA Revista da Associação Brasileira de Teoria e Análise Musical 2019, v. 4, n. 1, p. 30-61 - Journal of the Brazilian Society for Music Theory and Analysis@ TeMA 2019 - ISSN 2525-5541

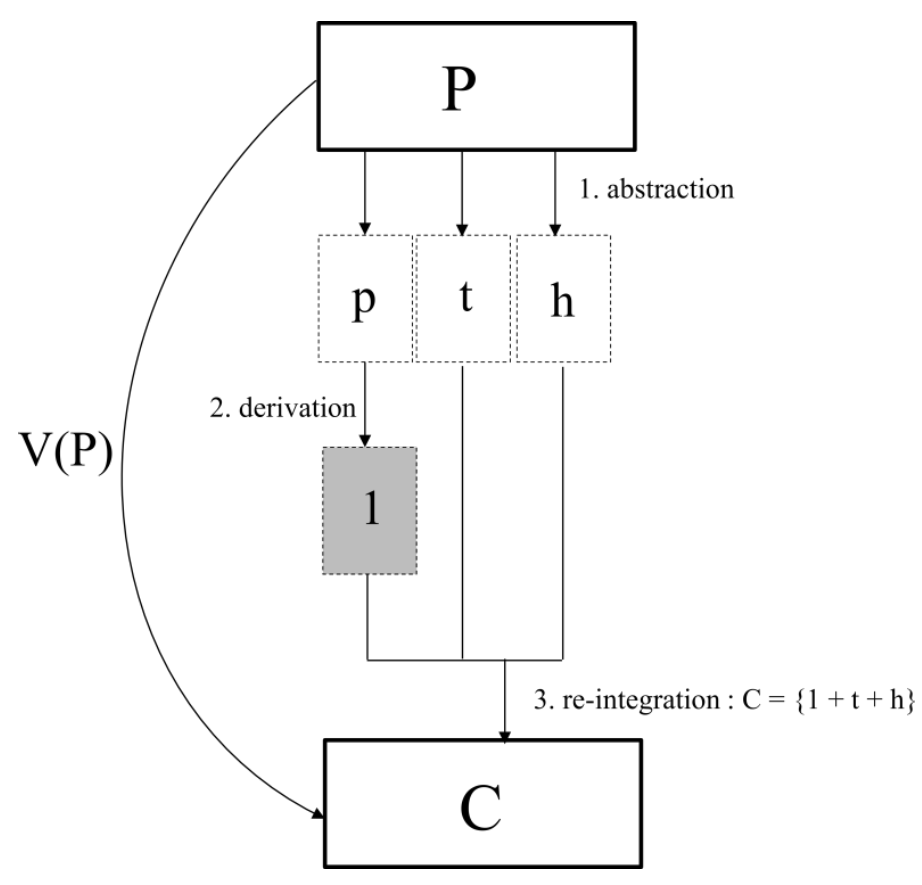

Figure 5: General representation of a decomposable derivative work

Decomposable variation can be classified in two distinct manners:

1. According to the number of stages of transformations required for its application. It can be:

- simple, when transformation occurs in only one stage, or

- compound, when transformation is performed in two or more stages.

2. According to the number of domains involved in the process. It can be:

- pure, when only one domain (for example, pitch) is affected by the transformation, or

- hybrid, if two (or, rarely, the three) domains are simultaneously involved in the derivative work.

A possible question that may naturally arise at this point addresses the differentiation between holistic and hybrid-type variations, since, at first impression, they seem to mean the same thing. In fact, it is not always easy to distinguish both situations. In strict terms, the former case corresponds exactly to a transformation that involves simultaneously all domains (in a practice sense, both pitch and temporal), a definition that could also be applied to the latter type. The subtle difference between them lies in the manner in which the process 
occurs. The label "hybrid variation" is suitable to describe those specific situations in which a complete transformation between two musical ideas can be decomposed into stages of secondary transformations, while in concrete variation that is not possible or, at least, would demand non-logical, very complicated, or far-fetched descriptions.

Using as models the schemes introduced in Figure 5, Figure 6 presents four examples of decomposable derivative work (Fig. 6a-d) combining the four possible combinations of classes (pure/simple, pure/compound, hybrid/simple, and hybrid/compound) in comparison with the holistic variation (Fig. 6d), which, obviously, does not present stages of abstraction and re-integration.

While simple decomposable variation is relatively easy to be identified with precision in analytical situations, compound variation is normally more problematic. In most part of the cases the task of tracking back the intermediary abstract-derivative stages that map P onto C can only be achieved by the analyst as a sequence of plausible hypotheses. 

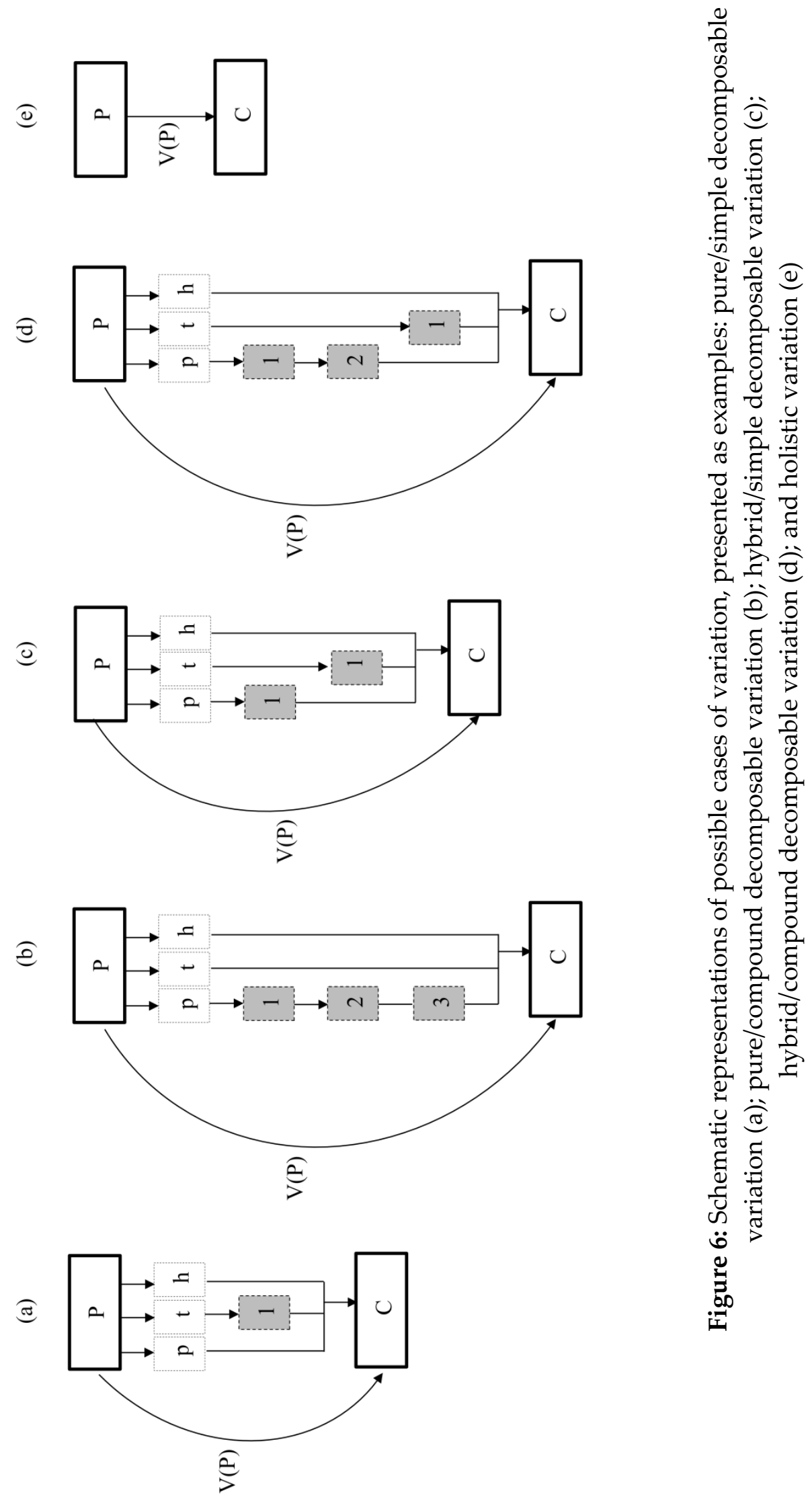


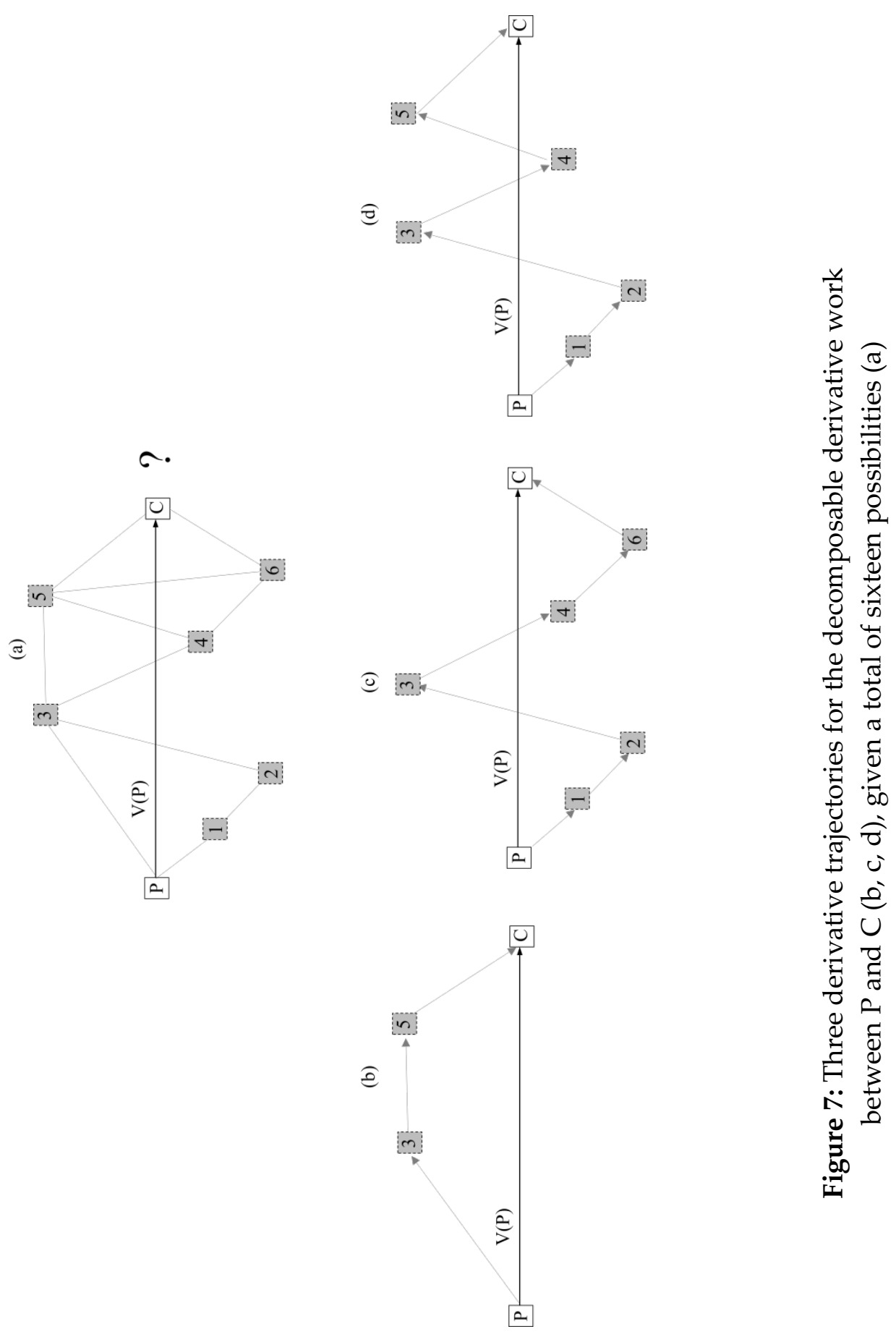

Figure 7 addresses this question. Let us assume that it as a simplified version of the model of Figure $6 \mathrm{~b}$ (pure/compound decomposable variation). ${ }^{11}$

${ }^{11}$ For clarity, both stages of abstraction and re-integration were omitted in the scheme, letting only derivation. 
Let us also suppose that an analyst considers variants 1,2,3, 4, 5, and 6 as possible intermediary, abstract "stations" between P and C. Considering that the edges in Figure 7a represent valid connections between the stations, ${ }^{12}$ sixteenth distinct trajectories would be possible, three of them depicted in Figure $7 \mathrm{~b}, \mathrm{c}$, and $\mathrm{d} .{ }^{13}$ Assuming that there is not a unique correct "answer" for the "problem", how would be the best choice for the analyst? If disregarded the context (a very important factor in real situations), maybe the most logical, and well-equilibrated approach should be the selection of the option with lesser number of stations (alternative $b$, in this case), and/or that in which the changes are more gradual (this decision would demand an evaluation of the real musical situations, not accessible in this simple example).

An interesting and pertinent metaphor originated in the fields of paleontology and evolutionary biology can be used for comparison. The complete sequence of intermediary evolutive stages for connecting two corelated forms of life (say, dinosaurs and birds) is virtually impossible to be concretely evidenced, due to the absence of the complete fossil register: most of the myriad of variations, species, genera, etc. that would fill this gap simply lived and disappeared without traces. However, the meticulous study of the rare fossils preserved combined with accumulated knowledge, powerful technology, cooperative work, and experience, allow the scientists to reconstruct with a high degree of accuracy the links, despite a time span measured in hundreds of millions of years. Although strongly supported by scientific methods, the reconstruction of the trajectory dinosaurs-birds is, strictly speaking, based on connective hypotheses.

Aside, evidently, the huge differences separating biological and musical realms, undoubtedly there also exist some interesting points of contact between them, reinforcing the metaphorical links. In this particular aspect, considering the scope of MDA, the analytical tasks of identification of variants that act in a

\footnotetext{
12 These "stations" are formally named hypothetic intermediary stages (HIS) in analytical situations. They will be resumed in section 4 .

${ }^{13}$ These trajectories, graphic representations of decomposable derivative work, will be treated as model for the derivative networks in section 4 .
} 
piece of music, and of explanation of their derivation from the respective referential ideas is many times dependent on plausible conjectures. ${ }^{14}$

It is worth to add that the hypotheses eventually established by an analyst do not intend to reconstruct the compositional lines of thought. They should rather be seen as a methodological strategy that aims to contribute for the systematization of the analysis.

\section{Transformational operations}

Up to this point, variation was described as a generic function $\mathrm{V}$, capable to transform a given referential musical idea P. As it was also mentioned, the outcome of such transformation (namely, the variant $\mathrm{C}$ ) is related to $\mathrm{P}$ by some degree of similarity, which can be systematically measured in MDA. ${ }^{15}$ In sum, in an archetypical derivative work we can affirm that $\mathrm{C}$ derives from $\mathrm{P}$, maintaining with this some degree of similarity. However, up to now nothing was said about how $\mathrm{P}$ may be transformed into $\mathrm{C}$, or in which manners the application of $\mathrm{V}$ can affect $P$. These questions will be properly addressed in the present section with the aid of a new concept, the transformational operations. A transformational operation, or simply operation, corresponds therefore to a specific manifestation of the generic function $\mathrm{V}$, as an algorithm or set of rules to be applied to an also specific referential element, which can be the complete idea $\mathrm{P}$ (in the case of holistic variation), or, considering decomposable variation, an element of a domain or even a subset of it. ${ }^{16}$

\footnotetext{
${ }^{14}$ Commenting a motivic analysis of Beethoven's String Quartet Op. 135/4 $4^{\text {th }}$ movement, made by Schoenberg, Michael Schiano (1992, p. 129-130) points out the fact that Schoenberg proposed some possible intermediary variants (that are not in the score) as plausive explanations of the connections between some of the ideas. In his words, "The events that Schoenberg wishes to connect exist on the musical surface. However, the intermediate steps are hypothetical (...) a chain of logical steps between two events is made explicit". As one can perceive, there are interesting similarities between Schoenberg's analytical procedures (as well as the methods developed by Schiano himself) and the present proposal.

${ }^{15}$ As previously stated, the description of the algorithms used for measurement of similarity is not addressed in the present article.

${ }^{16}$ Although it is also possible to consider operations in the realm of holistic variation, I will not explore this issue here, opting to set the focus on decomposable operations. The main reason is that holistic operations are normally strongly idiosyncratic and context-dependent, which prevents proper systematization. From now on, the use of the term "operation" in this section will refer exclusively to decomposable variation.
} 
MUSICA THEORICA Revista da Associação Brasileira de Teoria e Análise Musical 2019, v. 4, n. 1, p. 30-61 - Journal of the Brazilian Society for Music Theory and Analysis@ TeMA 2019 - ISSN 2525-5541

In formal terms, one can express a given (decomposable) operation as a function $v$, whose argument, the parent $\rho$, is an abstracted element of the referential idea $\mathrm{P}$, and whose output (child) $\gamma$, is a related transformation of $\rho$, therefore, also an abstract element. Equation 2 derived from Equation 1 exposes formally the basic syntactic structure of the action of an operation.

$$
\gamma=v(\rho)
$$

\section{Equation 2}

At this point, it is possible to propose a representation of decomposable variation, by including the new elements $Q, \gamma$, and $v$, as shown in Figure 8.

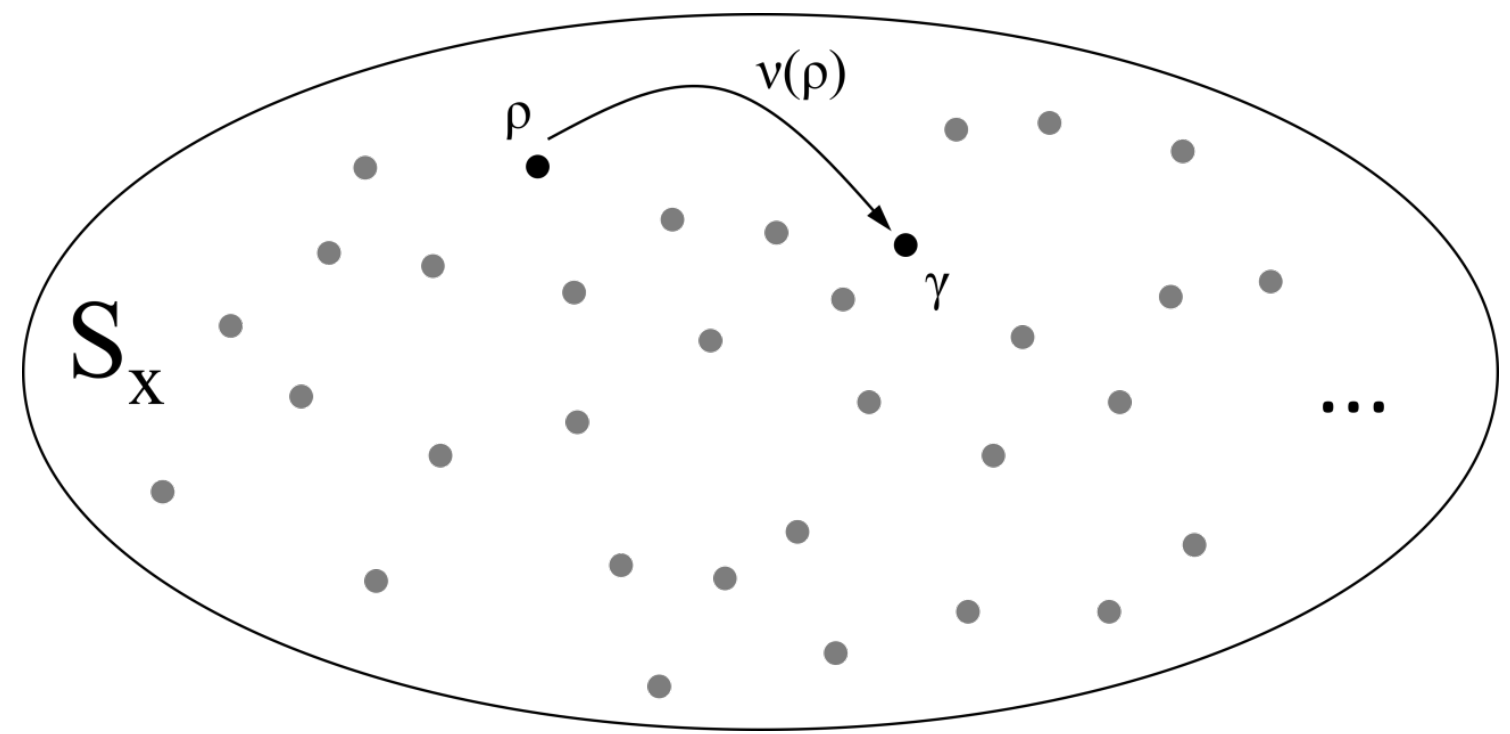

Figure 8: Representation of the action of function $v$ on set $S_{x}$

In this diagram $v$ represents, as already known, a more specific transformational function. As a matter of fact, $v$ (like V) can be seen as a conceptually infinite set (Fig. 9) that contains all possible kinds of transformations (operations, in the present terminology) capable to send a given Q to a related $\gamma$ in a domain-compatible set $S_{x}$. 


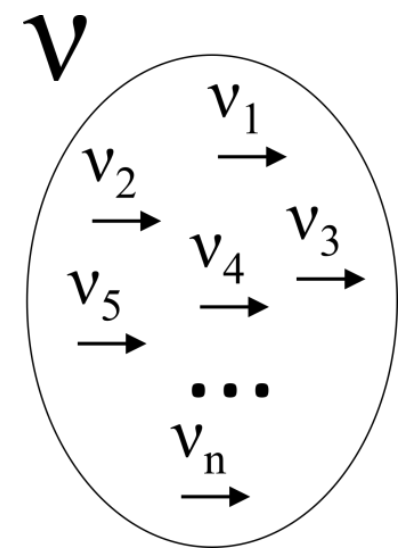

Figure 9: Set $v$ of operations

Consequently, one can think of a number (conceptually also infinite) possible derivations $(\gamma)$ from a given referential $\mathrm{Q}$, through applications of operations which are members of set $v$. In more informal terms, it is possible to obtain an offspring of variants of any size from Q, as suggested in Figure 10. In this scenery, the functions $v_{1}, v_{2}, v_{3}$, etc., represent real specific instances of operations, elements which will be described ahead.

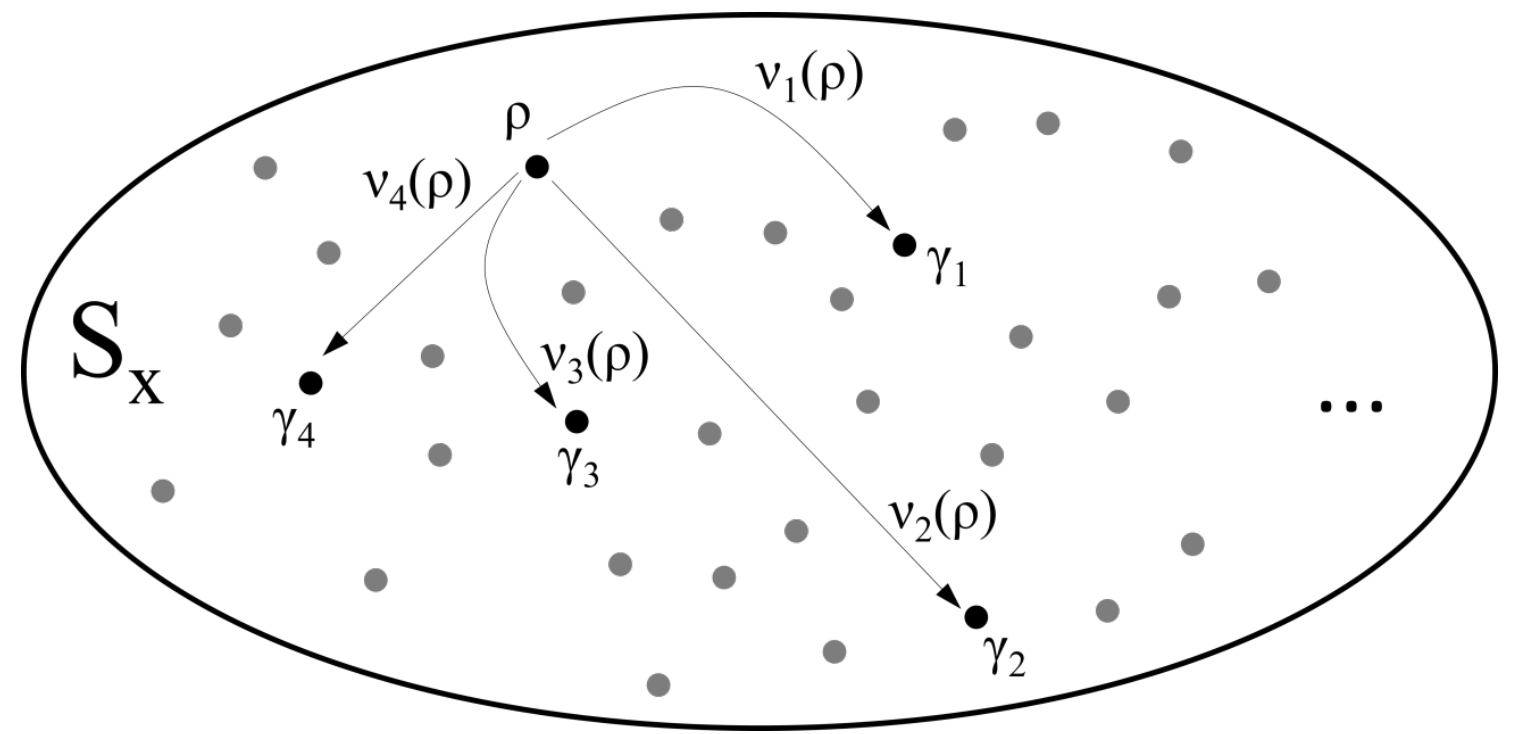

Figure 10: Action of functions v1-4

Operations are here classified according to two categories: type and scope of the argument.

Concerning the first category, operations are classified as canonic and noncanonic. The former type corresponds to "classical" instances of transformation. The canonic operations considered in MDA are: transposition (chromatic and 
diatonic), inversion (chromatic and diatonic), retrogradation, augmentation, and diminution. Non-canonic types comprise any possibility out of the canonic category, forming a conceptually infinite set of possibilities (22 non-canonic operations are currently considered in MDA). A symbolic notation is used for designating both types in analysis, according to the following conventions:

- Canonic operations are identified by a unique bold, uppercase letter $^{17}$ (generally, the initial of the operation's name), for example: augmentation $(\mathbf{A})$, retrogradation $(\mathbf{R})$, chromatic transposition $(\mathbf{T})$, diatonic transposition $(\mathbf{t})$, etc.

- Non-canonic operations are identified by an acronym formed by three bold, uppercase letters (preferentially, but not necessarily, the initial letters of the operation's name), for example: addition (ADD), permutation (PER), metric displacement (MTR), change of register (OCT), etc. ${ }^{18}$

Regarding the category "scope", as before stated, the argument of an operation $v$ can be the integral parent $\rho$ or a subset of it (which is generically labeled as $\mu$ ). While the former case corresponds to the conventional situation in decomposable variation (and, accordingly, will be called "normal"), the latter will be classified as mutational operation, a very important element in this theoretical proposal. Like mutations that occur inside the nucleus of living cells, mutational operations promote in a musical context microvariations, resulting normally in a very subtle transformation.

The notation of the argument of a mutational operation differs from the normal case by the indication of the subset of application, after a comma.

$$
\gamma=v(\rho, \mu)
$$

\section{Equation 3}

\footnotetext{
17 With the exception of diatonic versions of chromatic operations, that use lowercase letter as symbol.

${ }^{18}$ Some operations require special, complementary symbology for a more precise identification of its transformational action. The complementary symbol is subscripted at the right of the identification letter (or acronym, in the case of non-canonic type) of the respective operation, and can be a number or a typographic sign. There are several specific situations (some of them will be detailed in further examples) to which the complementary symbols refer, being also associated with the nature of the operation itself. Examples: $\mathbf{T}_{3}, \mathbf{O C T}_{+}, \mathbf{A D D}_{5}$, etc.
} 
where $\mu$ is a subset of $Q$, the very argument to be transformed by the operation. ${ }^{19}$

Figure $11 a-b$ provides generic schemes of the actions of normal and mutational operations. ${ }^{20}$ Figure 11c depicts the normal application of operation canonic augmentation (A) to the whole rhythmic structure (Q) of a given idea P. The same operation is mutationally applied to the second element of $\varrho$ (a specific instance of $\mu$ ) in Figure 11d.

(a)

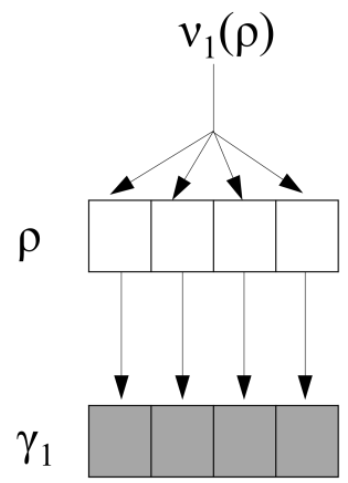

(b)

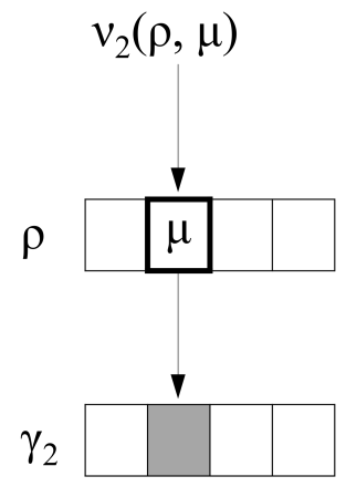

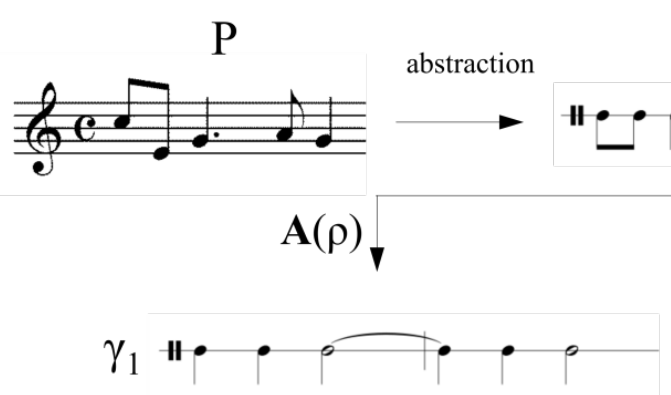

(c)

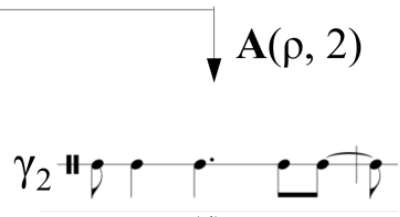

(d)

Figure 11a-d: Generic representation of the action of normal (a) and mutational operations (b), and respective examples, applying to an abstracted temporal sequence the operation augmentation (A), both in normal (c) and mutational (d) scopes

Table 1 lists in alphabetic order the 29 operations currently considered in MDA.

${ }^{19}$ In the case of normal operations $\rho$ is the unique argument of $v$.

${ }^{20}$ An operation has a dual nature if it can be presented in both versions, normal and mutational. 
MUSICA THEORICA Revista da Associação Brasileira de Teoria e Análise Musical 2019, v. 4, n. 1, p. 30-61 - Journal of the Brazilian Society for Music Theory and Analysis@ TeMA 2019 - ISSN 2525-5541

\begin{tabular}{|c|c|c|c|c|}
\hline operation & symbol & domain & scope & description \\
\hline addition & ADD & $\mathrm{p}, \mathrm{t}$ & d & $\begin{array}{l}\text { Adds a fixed amount to selected pitches or } \\
\text { durations }\end{array}$ \\
\hline augmentation & $\mathbf{A}$ & $t$ & $\mathrm{~d}$ & Duplicates selected durations \\
\hline chord-insertion & CIN & $\mathrm{h}$ & $\mathrm{m}$ & Insert a chord in a harmonic sequence \\
\hline chord-suppression & CSP & $\mathrm{h}$ & $\mathrm{m}$ & $\begin{array}{l}\text { Suppress a selected chord from a harmonic } \\
\text { sequence }\end{array}$ \\
\hline chordal inversion & CHI & $\mathrm{h}$ & $\mathrm{m}$ & Changes the bass of a selected chord \\
\hline chromatic alteration & ALT & $\mathrm{p}$ & $\mathrm{m}$ & Alters a selected pitch chromatically \\
\hline chromatic inversion & I & $\mathrm{p}$ & $\mathrm{d}$ & Inverts the direction of chromatic intervals \\
\hline $\begin{array}{l}\text { chromatic } \\
\text { transposition }\end{array}$ & $\mathrm{T}$ & $\mathrm{p}$ & d & $\begin{array}{l}\text { Adds a fixed amount to selected chromatic } \\
\text { intervals }\end{array}$ \\
\hline deletion & DEL & $\mathrm{p}, \mathrm{t}$ & $\mathrm{m}$ & $\begin{array}{l}\text { Suppress selected pitch or duration inside a pitch } \\
\text { or durational sequence }\end{array}$ \\
\hline diatonic inversion & $\mathbf{i}$ & $\mathrm{p}$ & $\mathrm{d}$ & Inverts the direction of selected diatonic intervals \\
\hline $\begin{array}{l}\text { diatonic } \\
\text { transposition }\end{array}$ & $\mathbf{t}$ & $\mathrm{p}$ & d & Adds a fixed amount to selected diatonic intervals \\
\hline diminution & D & $\mathrm{t}$ & $\mathrm{d}$ & Divides by two selected durations \\
\hline extension & EXT & $\mathrm{p}, \mathrm{t}$ & $\mathrm{n}$ & $\begin{array}{l}\text { Adds new pitches or durations at the end of a pitch } \\
\text { or durational sequence }\end{array}$ \\
\hline interpolation & INT & $\mathrm{p}, \mathrm{t}$ & $\mathrm{m}$ & $\begin{array}{l}\text { Inserts new pitches or durations into a pitch or } \\
\text { durational sequence }\end{array}$ \\
\hline $\begin{array}{l}\text { merging of } \\
\text { durations }\end{array}$ & MRG & $\mathrm{t}$ & $\mathrm{m}$ & Merges two contiguous duration \\
\hline metric displacement & MTD & $\mathrm{t}$ & $\mathrm{n}$ & $\begin{array}{l}\text { Displaces a rhythmic sequence by some amount of } \\
\text { time }\end{array}$ \\
\hline mode-change & MOD & $\mathrm{p}, \mathrm{h}$ & $\mathrm{n}$ & $\begin{array}{l}\text { Change the mode of a pitch and harmonic } \\
\text { sequence }\end{array}$ \\
\hline modulation & MDL & $\mathrm{h}$ & $\mathrm{n}$ & $\begin{array}{l}\text { Transposes the harmonic sequence by some fixed } \\
\text { interval }\end{array}$ \\
\hline permutation & PER & $\mathrm{p}, \mathrm{t}$ & $\mathrm{m}$ & $\begin{array}{l}\text { Permutates the order two elements of a pitch or } \\
\text { durational sequence }\end{array}$ \\
\hline re-division & RDV & $\mathrm{t}$ & $\mathrm{m}$ & $\begin{array}{l}\text { Reformulates the values of two contiguous } \\
\text { durations }\end{array}$ \\
\hline register-change & OCT & $\mathrm{p}$ & $\mathrm{m}$ & Adds or subtracts an octave to a selected pitch \\
\hline re-harmonization & RHA & $\mathrm{h}$ & $\mathrm{m}$ & Changes the internal elements of a selected chord \\
\hline rest-substitution & RST & $\mathrm{t}$ & $\mathrm{m}$ & Replaces a selected duration by a rest \\
\hline replication & RPL & $\mathrm{p}, \mathrm{t}$ & $\mathrm{m}$ & Replicates a selected group of pitches or durations \\
\hline retrogradation & $\mathbf{R}$ & $\mathrm{p}, \mathrm{t}$ & $\mathrm{n}$ & Inverts the order of a pitch or durational sequence \\
\hline rotation & ROT & $\mathrm{p}, \mathrm{t}$ & $\mathrm{n}$ & $\begin{array}{l}\text { Sends the last element of a pitch or durational } \\
\text { sequence to the first position }\end{array}$ \\
\hline splitting of duration & SPL & $\mathrm{t}$ & $\mathrm{m}$ & Splits a selected duration in two \\
\hline subtraction & SUB & $\mathrm{p}, \mathrm{t}$ & d & $\begin{array}{l}\text { Subtracts a fixed amount to selected pitches or } \\
\text { durations }\end{array}$ \\
\hline suppression & SUP & $\mathrm{p}, \mathrm{t}$ & $\mathrm{m}$ & $\begin{array}{l}\text { Suppresses an element of the end of a sequence of } \\
\text { pitches or durations }\end{array}$ \\
\hline
\end{tabular}

Table 1: Chart of operations, considering name, symbol, domain (pitch, time or harmony), scope (normal, mutational or dual) and a brief description 
Given the obvious impossibility of providing proper illustration and commentary for the whole group of operations, for a question of space and scope, the following figures privilege just the cases that will be employed as examples in the next section of this article.
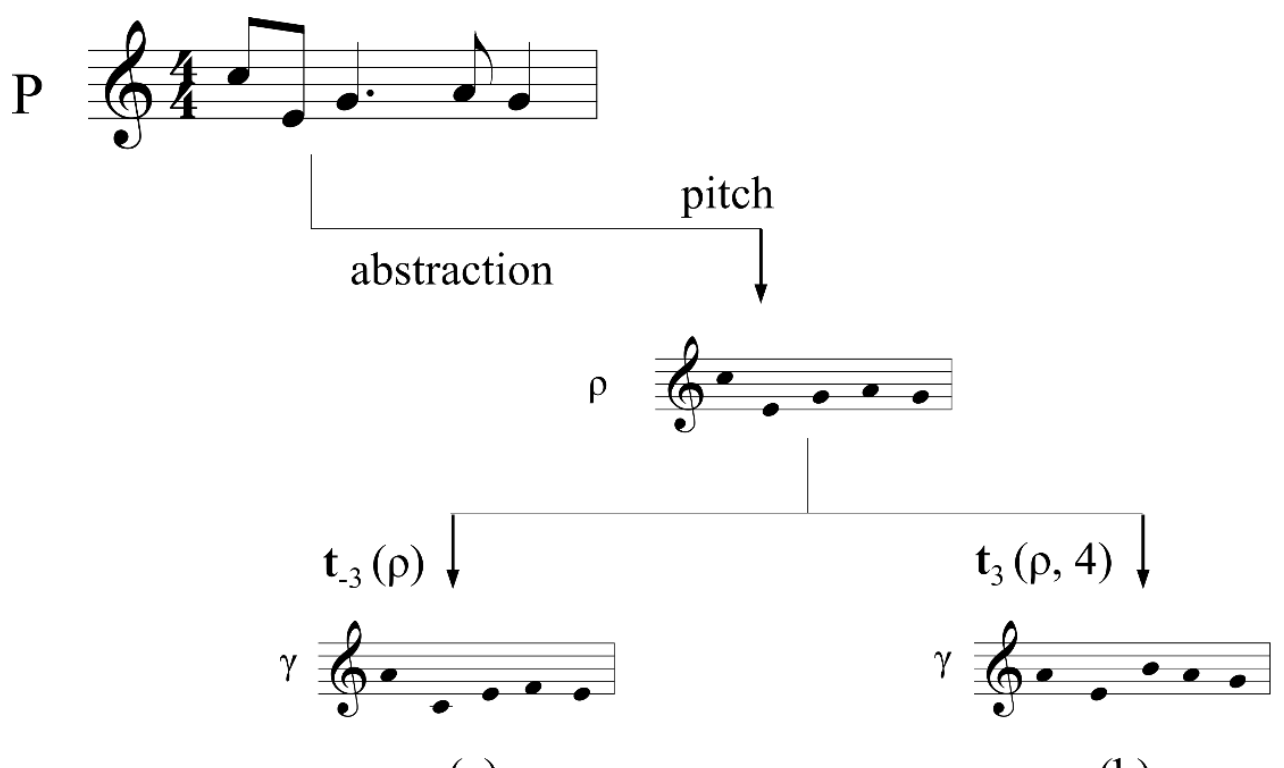

(a)

(b)

Figure 12: Example of application of operation diatonic transposition ( $\mathbf{t})$ : normal/pitch (a); mutational/pitch (b)

The canonic operation diatonic transposition $(\mathbf{t})$ is applied only to pitch domain, having dual scope (Fig. 12) The subscript added to the symbol indicates the diatonic interval ${ }^{21}$ of transposition. In (a) the whole pitch sequence is transposed down a diatonic third. In the mutational example (b), only the fourth element of the sequence is affected by the transposition (or else, $\mu=4$ ), this time an upward diatonic third (pitches $\mathrm{A} \rightarrow \mathrm{C}$ ).

Figure 13 presents two examples of another canonic operation, diminution (D), of exclusive application to the temporal domain. As it can be observed in the mutational situation (b), just the last duration is diminished (quarter to eight note), a very slight sort of transformation.

\footnotetext{
${ }^{21}$ Diatonic intervals do not concern intervallic quality (minor/major, perfect/diminished/ augmented), being measured only according to type: unison (1), second (2), third (3), etc. As a convention, descending diatonic intervals are indicated by a "minus" signal before the corresponding number (ex: “-5" = descending fifth).
} 
MUSICA THEORICA Revista da Associação Brasileira de Teoria e Análise Musical 2019, v. 4, n. 1, p. 30-61 - Journal of the Brazilian Society for Music Theory
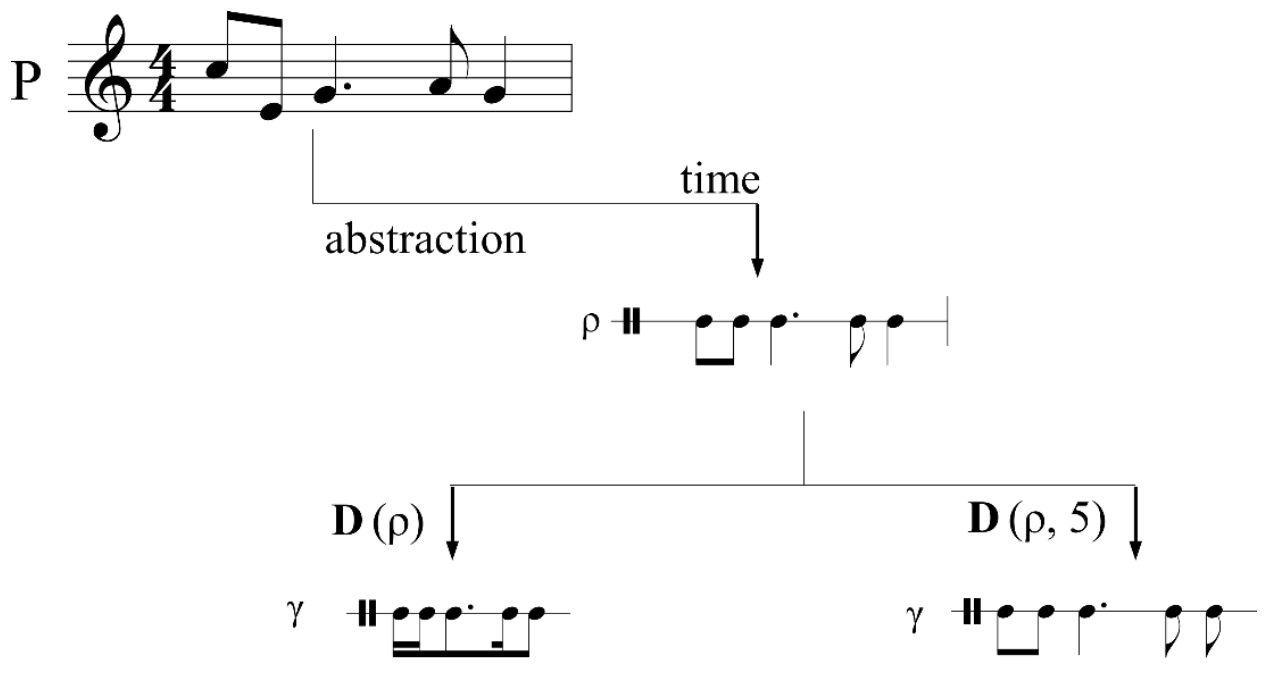

(a)

(b)

Figure 13a-b: Example of application of operation diminution (D): normal/time (a); mutational/time (b)

The two next examples address operations that are act only in mutational scope. In the case of register-change (OCT), an exclusively pitch transformation (Fig. 14), the first element is transposed an octave lower.

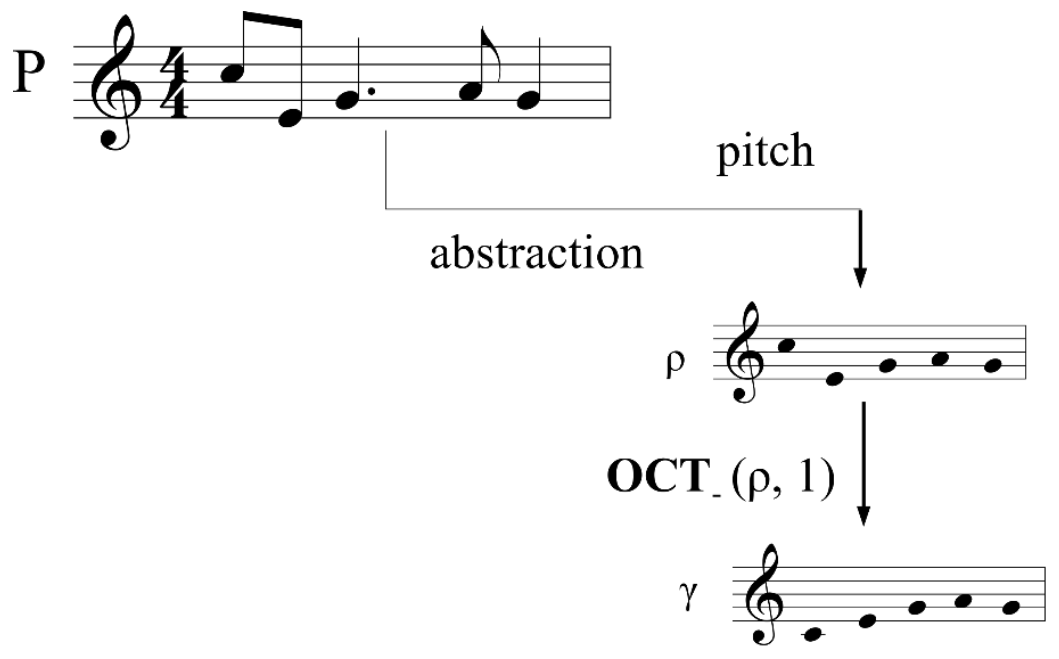

Figure 14: Example of application of operation register-change (OCT), mutational/pitch

Metric displacement (MTD) provokes a temporal dislocation of a given durational, keeping unaltered all internal proportions (Fig. 15).22

\footnotetext{
${ }^{22}$ In the case of this example the sequence is dislocated to the "right" (in the bar) by two unities (by convention, each durational unity corresponds to a sixteenth note). "Negative" dislocations (i.e., leftwards) are also possible (see Fig. 19).
} 


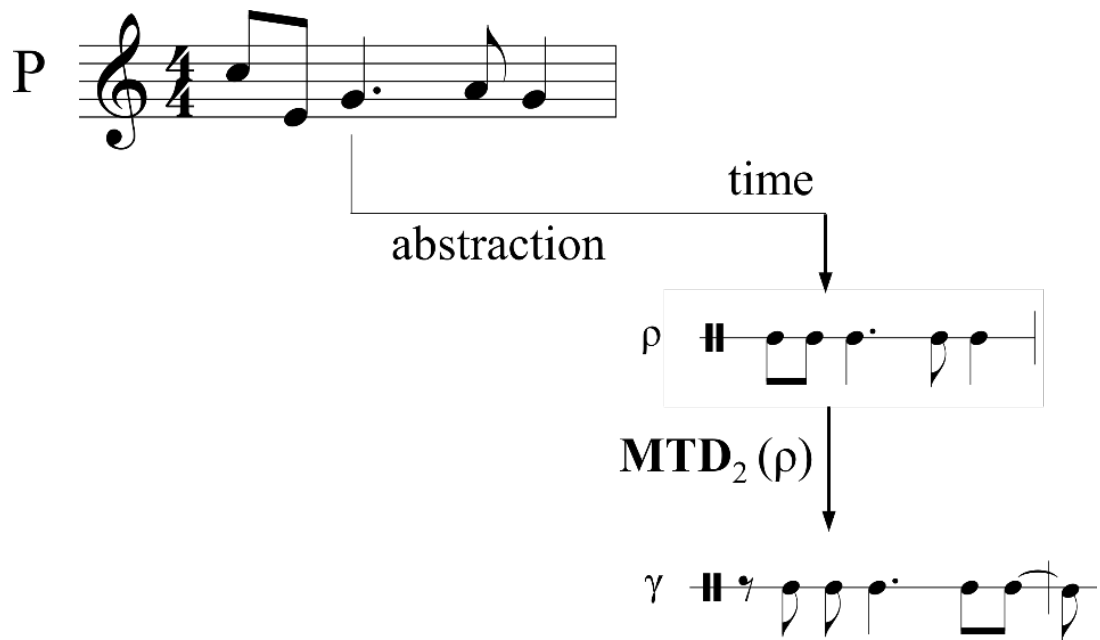

Figure 15: Example of application of operation metric displacement (MTD): normal/time

The last final examples consider operations that can be applied to pitch and temporal domains. Figure 16 depicts two instances of permutation (PER), with application exclusively mutational. In this transformation two (non-necessarily contiguous) elements of sequence change their positions: second and fourth pitches (a) and fourth and fifth durations (b).

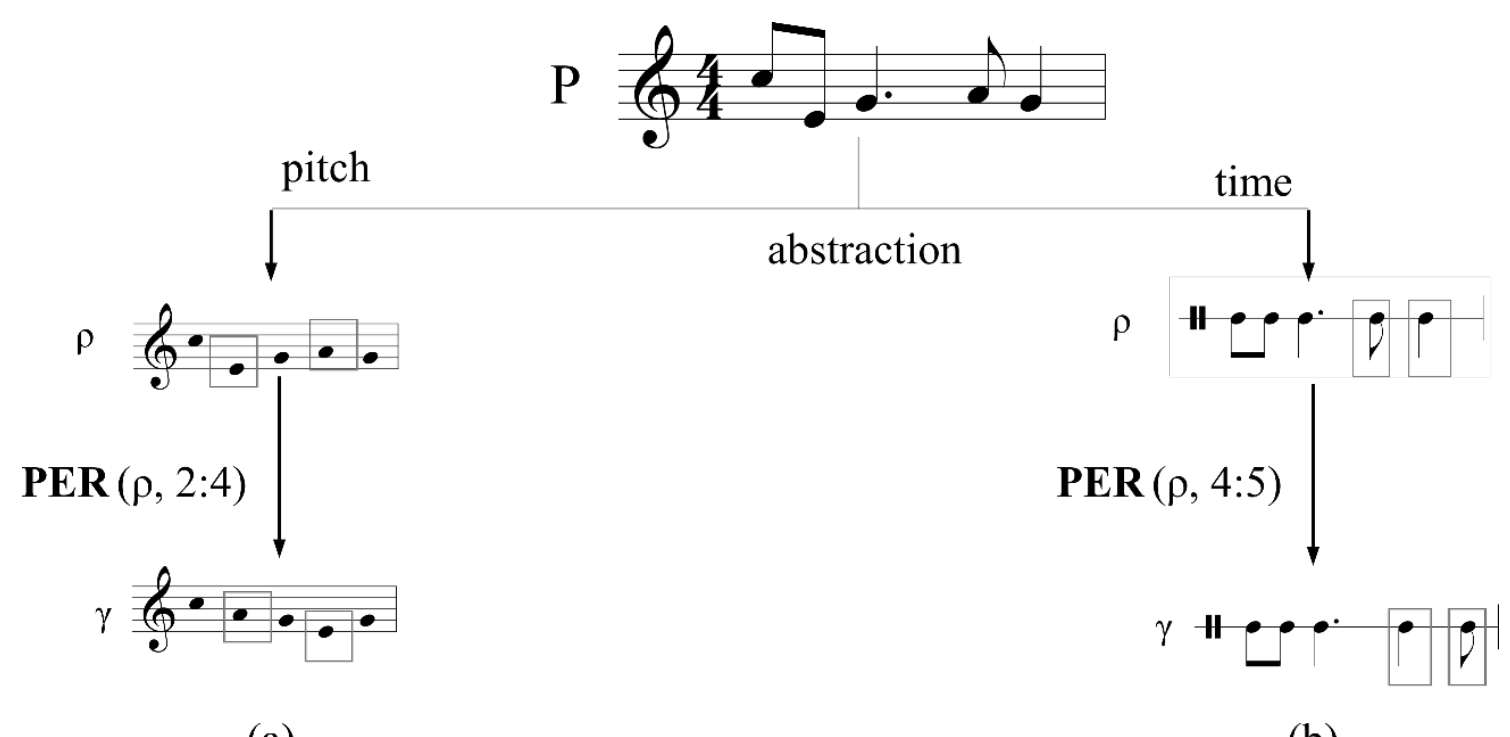

(a)

(b)

Figure 16: Example of application of operation permutation (PER): mutational/pitch (a); mutational/time (b)

Operation addition (ADD) affects intervals (in the pitch domain) and durations (temporal domain) by adding a fixed amount of unities (indicated by 
a subscript number at the right of the symbol). ${ }^{23}$ Unlike PER, ADD is associated with a dual scope. Figure 17 presents four examples of transformation, considering normal and mutational scopes in pitch domain $(\mathrm{a}-\mathrm{b})$, and normal and mutational scopes in temporal domain (d).

\section{Transformational analysis and derivative networks}

Knowledge about operations is central for determining derivative paths in analytical situations, in a process that from now will be called transformational analysis. As it was briefly suggested in section 1, it involves normally the elaboration of hypothetical intermediary stages (identified by the acronym HIS) of plausible derivations connecting a given musical idea $\mathrm{C}$ to its presumed origin P. Methodologically, transformational analysis is made through successive reductions (resembling those used in Schenkerian analysis) that gradually suggest the possible operations employed along the process.

In order to demonstrate succinctly the potentialities of the transformational analysis, let $\mathrm{C}$ be a concrete musical idea which was classified as a variant of a referential idea $\mathrm{P}$ in a hypothetic analytical situation (Fig. 18). Transformational analysis proposes to the analyst the following basic question: How could you systematically explain the chain of transformations that would map C onto P?

${ }^{23}$ The unity considered in pitch domain is the semitone. 


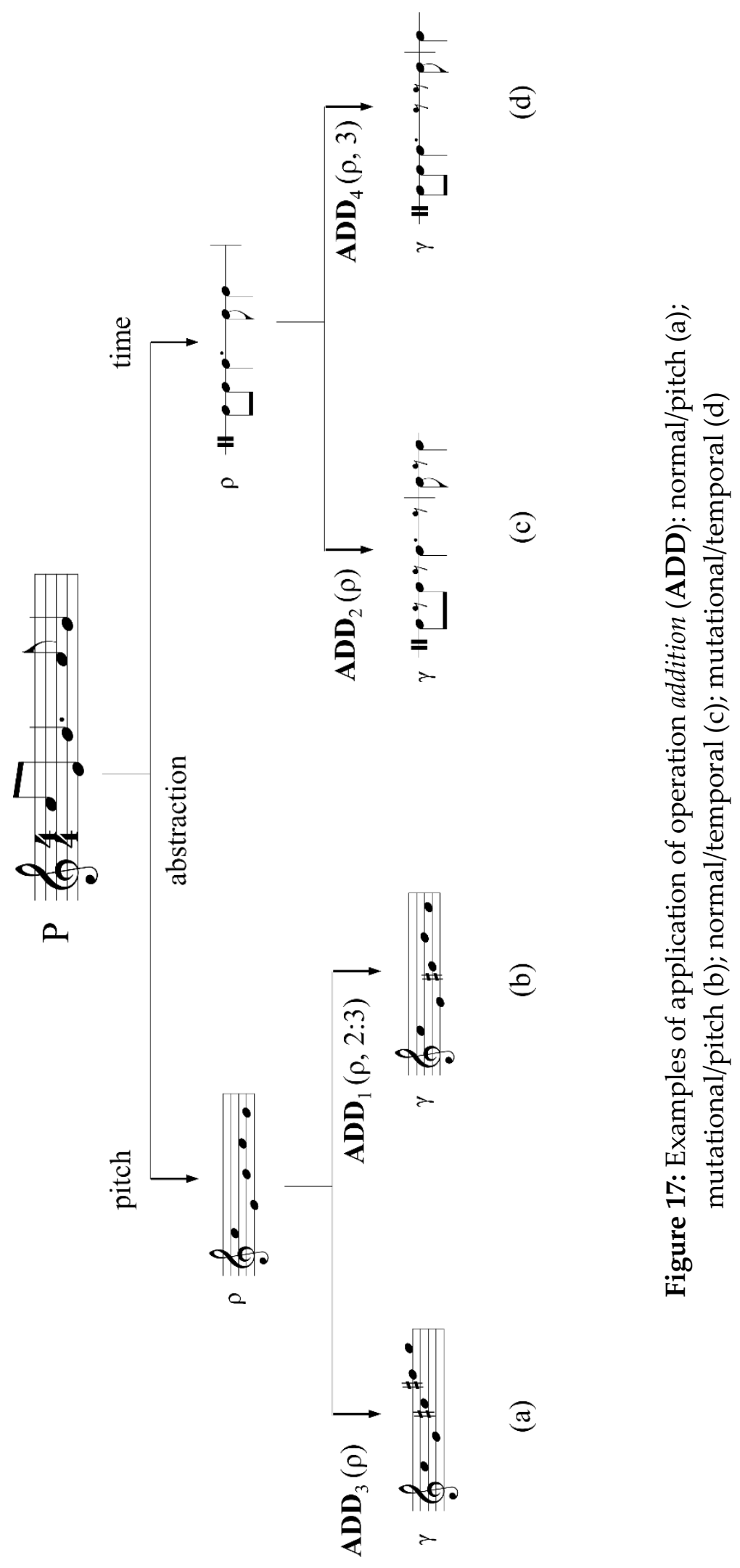




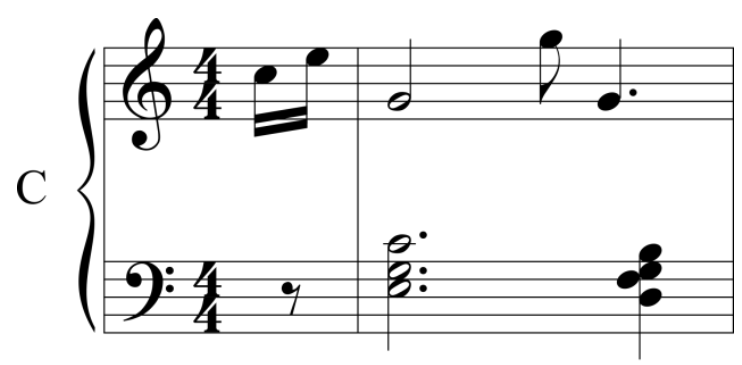

$\Delta$

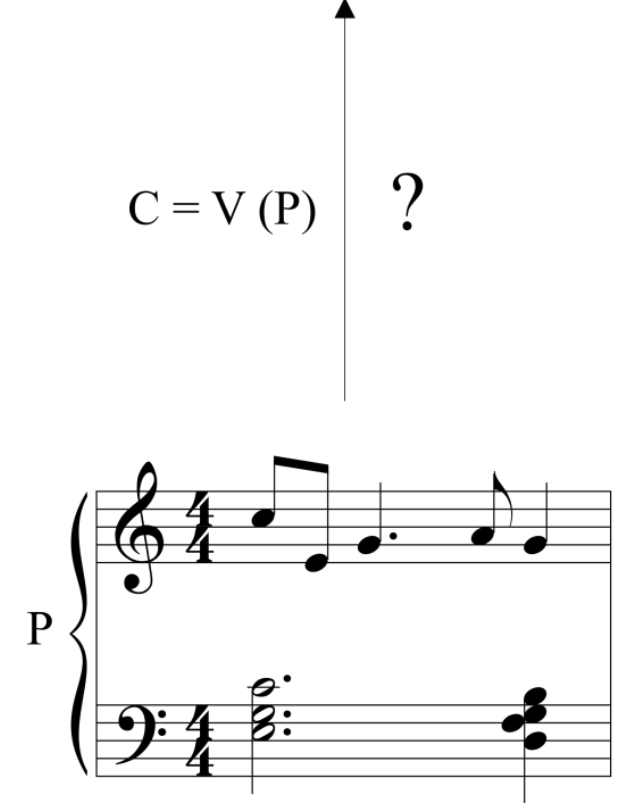

Figure 18: derivative relation between musical ideas $P$ and $C$

Suppose that the analyst, after a meticulous examination, decides by a derivative "narrative" based on six transformations distributed by both domains of pitch and time. ${ }^{24}$ The solution for the question, therefore, corresponds to a case of compound/hybrid variation, modeling the scheme of Figure 6b. Figure 19 presents a possible (since a transformational analysis is always based on hypotheses) transformational analysis of the path $\mathrm{C} \rightarrow \mathrm{P}$.

${ }^{24}$ The ways by which he/she supposedly reached these specific conclusions are not here relevant, but I think that they are clearly evident in the example. 


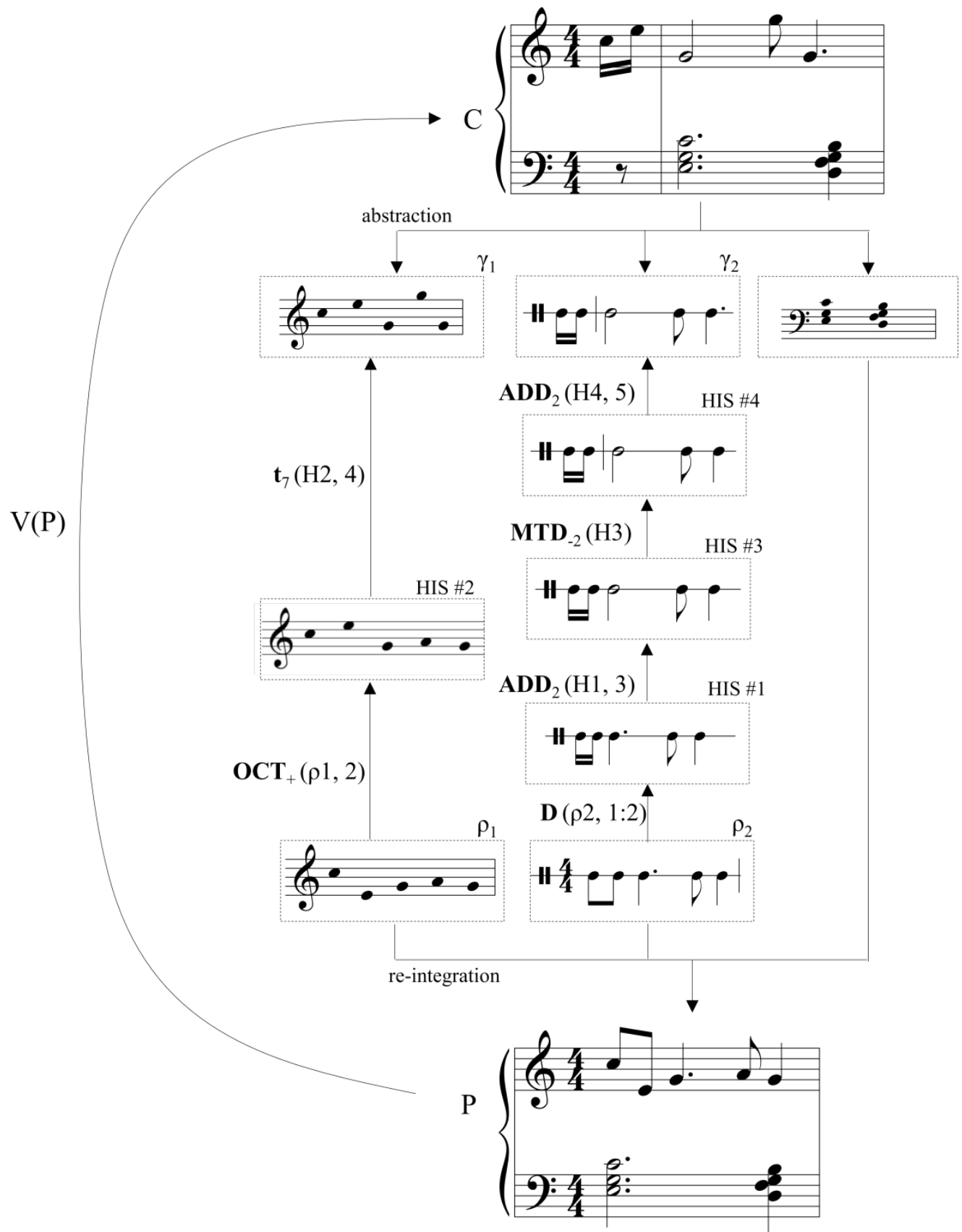

Figure 19: Example of transformational analysis considering compound/hybrid abstract variation

Notice that the arrows related to the generic function $\mathrm{V}$ and the six abstract operations point to the direction bottom-up, instead of top-down, as in Figure 6b. This modification of the model is justified by the fact that transformational analysis is a sequence of proposed hypotheses whose main goal is to reconstruct a possible derivative path, through logical reasoning and the use of simple means. 
MUSICA THEORICA Revista da Associação Brasileira de Teoria e Análise Musical 2019, v. 4, n. 1, p. 30-61 - Journal of the Brazilian Society for Music Theory and Analysis@ TeMA 2019 - ISSN 2525-5541

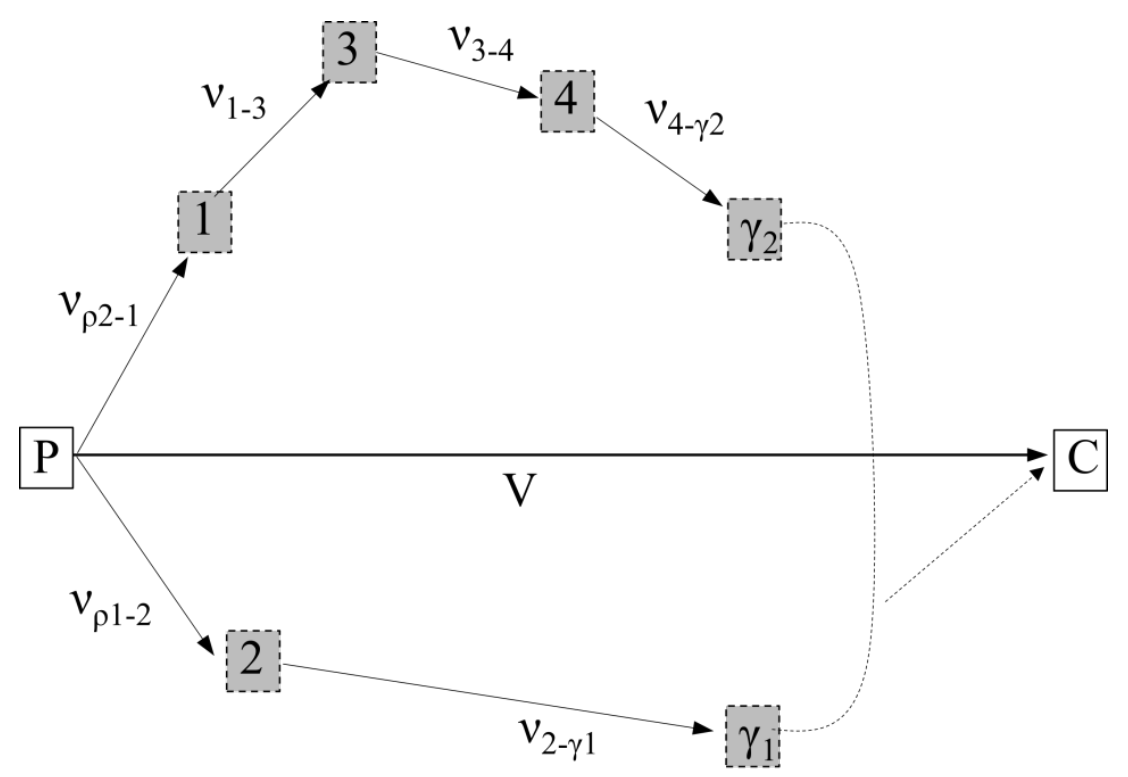

\begin{tabular}{c|c|c|c} 
op. & label & domain & scope \\
\hline$v_{\rho 2-1}$ & $\mathbf{D}$ & time & normal \\
\hline$v_{\rho 2-2}$ & OCT & pitch & mutational \\
\hline$v_{2-3}$ & ADD & time & mutational \\
\hline$v_{3-4}$ & MTD & time & mutational \\
\hline$v_{2-\gamma 1}$ & $\mathbf{i}$ & pitch & mutational \\
\hline$v_{3-\gamma 2}$ & ADD & time & mutational
\end{tabular}

Figure 20: Transformational network related to Figure 19

Figure 20 provides a concise graphical representation for the transformational analysis of Figure 19, following the model previously sketched in Figure 7. In MDA this graphical scheme is called derivative network. ${ }^{25} \mathrm{~A}$ derivative network essentially depicts the information necessary for explaining the elements of a given transformational process, having the following characteristics:

${ }^{25}$ The idea of derivative network adapts elements of the models proposed by David Lewin (1987), David Kopp (2002), and Steve Rings (2011). 
a) The musical (concrete) ideas $\mathrm{P}$ and $\mathrm{C}$ are linked by a horizontal, leftright arrow representing the generic function $\mathrm{V}$ (the direction of the arrow indicates that $\mathrm{C}$ is derived from $\mathrm{P}$ );

b) For simplicity, the stage of abstraction is omitted from the network;

c) For the same reason, the domains that are not affected by transformations (harmony, in the case of Fig. 19) are also omitted;

d) The stage of re-combination is indicated by a dashed arrow connecting the derivative targets ( $\gamma_{1}$ and $\gamma_{2}$ in Fig. 20) and the concrete unity C;

e) As a convention, derivations related to time domain are depicted arranged to the "north" of line $\mathrm{P}-\mathrm{C}$, while those referred to pitch and harmony occupy the "south" position;

f) Intermediary stages are disposed according to a hypothetical temporal order (previously determined by the analyst) in the respective domain/spaces (time/north and pitch-harmony/south). Angles and sizes of the connecting arrows are arbitrary, oriented just by layout conveniences;

g) Names, domains, and scopes of the employed operations are also provided in a table format, as complementary information.

\section{A transformational typology of developing variation}

Under the present transformational bias of MDA, developing variation (DV) can be concisely defined as a process that encompasses sequential, correlated variations occurring in function of time. ${ }^{26}$ In other terms, DV interconnects isolated transformations in a chain of related actions highly dependent on contextual conditions. Conversely, the "ordinary" derivative work (whose archetypical representation is shown in Fig. 2) is inherently a noncontextualized kind of transformational action and, therefore, can be considered as a, so to speak, timeless process. Based on this conception, I propose also the introduction of a new concept, the unity of developing-variation work, or UDV, whose archetypical representation is depicted in Figure 21.

\footnotetext{
${ }^{26}$ For two comprehensive, "conventional" definitions of developing variation (among many others), see Frisch (1984, p. 9) and Haimo (1997, p. 351).
} 


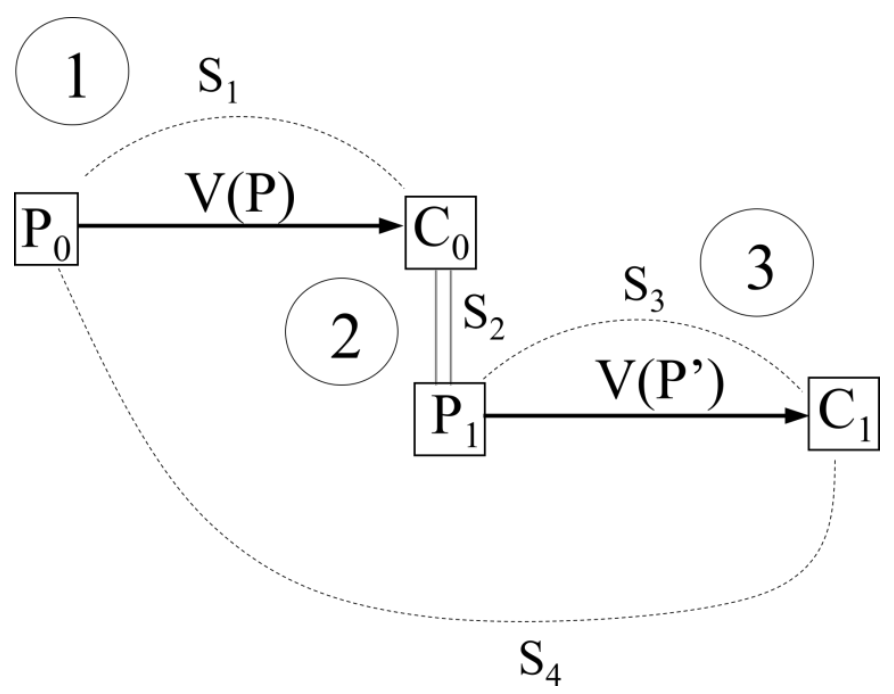

Figure 21: Archetypical representation of a unity of developing-variation work considering steps 1 (first derivation), 2 (child-parent equivalence), and 3 (second derivation)

A UDV presents the minimal, and sufficient conditions for establishing a developing variation process, being therefore labeled as a first-order developingvariation work (DV1). It is composed by three sequential steps: (1) first derivation $\left(\mathrm{P}_{0} \rightarrow \mathrm{C}_{0}\right)$, as a conventional archetypical derivative work; (2) child-parent equivalence, in which the child of the previous stage becomes the parent for the next $\left(\mathrm{C}_{0}=\mathrm{P}_{1}\right)$; and (3) second derivation $\left(\mathrm{P}_{1} \rightarrow \mathrm{C}_{2}\right)$, another derivative work, consequent of the first.

In sum, UDV corresponds to the junction of two simple archetypical derivative works, by an intermediary relation of equivalence acting analogously to a pivot chord in a tonal modulation. Four possible relations of similarity integrate a UDV:

$S_{1}$ : between $\mathrm{P}_{0}$ and $\mathrm{C}_{0}\left(\mathrm{~S}_{1}\right)$;

$\mathrm{S}_{2}$ : between $\mathrm{C}_{0}$ and $\mathrm{P}_{1}$, necessarily equal to $1,{ }^{27}$ considering their obligatory equivalence;

$S_{3}$ : between $P_{1}$ and $C_{1}$;

$\mathrm{S}_{4}$ : between $\mathrm{P}_{0}$ and $\mathrm{C}_{1}$.

This last relation is the most significative, and important in a developingvariation work. Although exceptions can occur, $\mathrm{S}_{4}$ is expected to be lesser than $\mathrm{S}_{1}$,

\footnotetext{
${ }^{27}$ The maximum value of similarity, as previously stated.
} 
since as a rule DV tends to provoke continuous dilution of similarity between the $\mathrm{P}_{0}$ (or the primordial parent) and its subsequent descendants. ${ }^{28}$

From this, it is possible to propose a generalization of a nth-order developing-variation work (DVn) by "plugging" in series an indefinite number of UDVs, as shown in the model of Figure 22. Notice that eventually "unfertile" variants (indicated by empty rectangles) can be produced along the "generations". These are not relevant for DVn, which is represented only by the main branch of derivations, namely the UDV connections.

The similarity relation between the primordial parent $\mathrm{P}_{0}$ and a nth descendant is represented by the symbol $S_{n+3}$ (for example, the similarity relation between $\mathrm{P}_{0}$ and $\mathrm{C}_{8}$ will be labeled as $\mathrm{S}_{12}$ ). The measurement of this relation is one of the most important aspects of MDA, especially in analytical applications, a point to be examined in future studies.

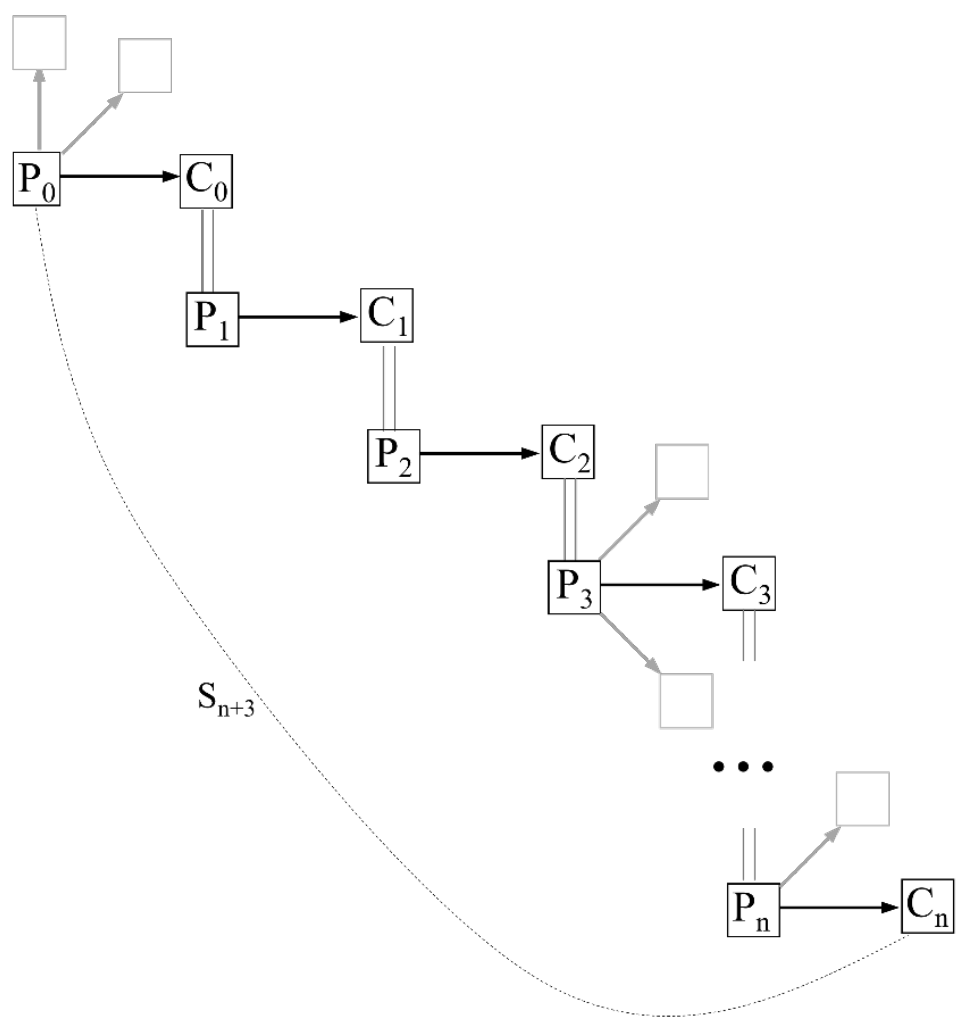

Figure 22: General scheme of a nth-order developing-variation work

\footnotetext{
${ }^{28}$ On the other hand, $\mathrm{S}_{1}$ and $\mathrm{S}_{3}$ are mutually independent and cannot be related based on a general assumption.
} 


\section{Concluding remarks}

The present article addressed the current version of the Model of Derivative Analysis, focusing on the main elements that form its theoretical basis. The interaction of the concepts, methods, and assumptions here introduced (like derivative work, abstract variation, hypothetical intermediary stages, transformational analysis, derivative network, operations, order and unity of development-variation work) contributes to reinforce the premise that variation as be seen as a generic action capable to transform musical ideas into others related by some degree of similarity.

Constrained by the limits of space and scope, several essential aspects of MDA have to be omitted (I would cite especially the algorithms for measurement of similarity, the concept of derivative space, the transformational Grundgestalt, among others) or treated superficially, or only partially (it is the cases of the transformational operations, and transformational analysis). These subjects will be properly addressed in complementary studies.

Another central question concerning the new configuration of the research is related to practical application. The methodology for derivative analysis derived from the theoretical framework described in this text was recently consolidated, providing a more systematic and formal means for derivative analysis. An article in preparation applying the method to a complete work composed by Brahms (the Intermezzo for piano Op. 118, no. 2) is intended to be its first large-scale test.

\section{References}

1. Almada, Carlos. 2016. Derivative Analysis and Serial Music: The Theme of Schoenberg's Orchestral Variations Op. 31. Permusi, 33, p. 1-24.

2. 2013. Simbologia e hereditariedade na formação de uma Grundgestalt: a primeira das Quatro Canções Op. 2 de Berg. Per Musi, 27, p. 7588.

3. . 2011a. A variação progressiva aplicada na geração de ideias temáticas. In: Simpósio Internacional de Musicologia, 2, Proceedings... Rio de Janeiro: UFRJ, p. 79-90. 
4 . 2010. O conceito de variação em desenvolvimento no primeiro movimento da Sonata para Piano Op. 2/1, de Beethoven. Música Hodie, 8/2, p. 83-94.

5. Auerbach, Brent. 2005. The Analytical Grundgestalt: A New Model and Methodology Based on the Music of Johannes Brahms. Thesis (PhD in Music). University of Rochester.

6. Carpenter, Patricia. 1983. Grundgestalt as tonal function. Music Theory Spectrum, 5, p. 15-38.

7. Collison, Stephen. 1994. Grundgestalt, Developing Variation, and Motivic Processes in the Music of Arnold Schoenberg: An Analytical Study of the String Quartets. Thesis (PhD in Music). King's College.

8. Epstein, David. 1980. Beyond Orpheus: Studies in music structure. Cambridge: The MIT Press.

9. Frisch, Walter. 1984. Brahms and the Principle of Developing Variation. Los Angeles: University of California Press.

10. Haimo, Ethan. 1990. Schoenberg's Serial Odyssey: The Evolution of His TwelveTone Method 1914-1928. Oxford: Clarendon Press.

11. 1997. Developing Variation and Schoenberg's Serial Music. Musical Analysis, 16/3, p. 349-365.

12. Lewin, David. 1987. Generalized Musical Intervals and Transformations. New Haven: Yale University Press.

13. Mayr, Desirée. 2018. The Identification of Developing Variation in Johannes Brahms Op.78 and Leopoldo Miguéz Op.14 Violin Sonatas through Derivative Analysis. Thesis (PhD in Music). Federal University of Rio de Janeiro.

14. Mayr, Desirée and Almada, Carlos. 2017. Correlations between Developing Variation and Genetic Processes in the Analysis of Brahms' Violin Sonata Op.78. In: European Congress of Musical Analysis, 9. Proceedings ... Strasbourg: EUROMAC (published as an extended abstract).

15. 2016. Use of Linkage Technique in Johannes Brahms' Op. 78 and Leopoldo Miguéz's Op. 14 Violin Sonatas. Opus, 22/2, p. 429-449.

16. Meyer, Leonard. 1989. Style and Music. Chicago: The University of Chicago Press.

17. Neff, Severine. 1984. Aspects of Grundgestalt in Schoenberg's First String Quartet, Op. 7. Journal of the Music Theory Society, 9/1-2, p. 7-56. 
MUSICA THEORICA Revista da Associação Brasileira de Teoria e Análise Musical 2019, v. 4, n. 1, p. 30-61 - Journal of the Brazilian Society for Music Theory and Analysis@ TeMA 2019 - ISSN 2525-5541

18. Ng, Yuet. 2005. A Grundgestalt Interpretation of Metric Dissonance in the Music of Brahms. Thesis (PhD in Music). Eastman School of Music, University of Rochester.

19. Rings, Steve. 2011. Tonality and Transformation. Oxford: Oxford University Press.

20. Rufer, Joseph. 1954. Composition with Twelve Notes. (Humphrey Searle, trad.). London: Rocklife.

21. Schiano, Michael. 1992. Arnold Schoenberg's Grundgestalt and its Influence. Thesis (PhD in Music). Brandeis University.

22. Schoenberg, Arnold. 1984. Style and Idea: Selected Writings of Arnold Schoenberg. London: Faber \& Faber. 